\title{
Níveis de dano Econômico para Decisão de Controle de Capim- ARROZ (Echinochloa spp.) EM ARROZ IRRIGADo (Oryza sativa) ${ }^{1}$
}

\author{
Economic Threshold Level for Barnyardgrass (Echinochloa spp.) Control Decision in Flooded \\ Rice (Oryza sativa)
}

\author{
GALON, L. ${ }^{2}$, AGOSTINETTO, D. ${ }^{3}$, MORAES, P.V.D. ${ }^{2}$, DAL MAGRO, T. ${ }^{2}$, PANOZZO, L.E. ${ }^{2}$, \\ BRANDOLT, R.R. ${ }^{4}$ e SANTOS, L.S. ${ }^{4}$
}

\begin{abstract}
RESUMO - O nível de dano econômico (NDE) para monitoramento das infestações de capimarroz em lavouras de arroz irrigado permite adotar medidas de manejo na cultura e usar herbicidas de maneira racional. Objetivou-se com o trabalho determinar NDE para capimarroz, presente em lavouras de arroz irrigado, calculado na base de um único ano, em função de populações de capim-arroz, de cultivares de arroz e de épocas de entrada de água na lavoura. Para isso, foram conduzidos dois experimentos em delineamento experimental completamente casualizado, sem repetição. No primeiro experimento, os tratamentos foram constituídos de seis cultivares de arroz: BRS-Atalanta e IRGA 421 (ciclo muito curto), IRGA 416, IRGA 417 e Avaxi (ciclo curto) e BRS-Fronteira (ciclo médio); e dez populações de capim-arroz. No segundo experimento usaram-se como tratamentos épocas de início da irrigação: 1, 10 e 20 dias após aplicação dos tratamentos herbicidas (DAT); e populações de capim-arroz. Os NDEs estimados para o capim-arroz variaram em função das práticas de manejo adotadas na cultura do arroz irrigado. Os NDEs estimados para os cultivares de arroz IRGA 416 e 417 foram superiores aos dos demais cultivares quando em competição com capim-arroz. O atraso da entrada de água diminui os NDEs para o cultivar de arroz BRS-Pelota. Aumentos nas perdas de produtividade por unidade de planta daninha, no potencial de produtividade da cultura, no valor do produto colhido e na eficiência do herbicida e diminuição do custo de controle reduziram os NDEs, tornando econômica a adoção de práticas de manejo sob baixas populações de capim-arroz em competição com arroz irrigado.
\end{abstract}

Palavras-chave: estudo econômico, manejo integrado, modelos matemáticos.

\begin{abstract}
Economic weed threshold (EWT) for monitoring barnyardgrass infestation in flooded rice farms allows the adoption of crop management measurements and a rational use of herbicide. The objective of this study was to determine EWT for barnyardgrass based on a single year in function of barnyardgrass populations, rice varieties and flooding timings. Thus, two trials were carried out using a completely randomized design with no replications. The first trial treatments consisted of six rice varieties: BRS-Atalanta, IRGA 421 (very short cycle); IRGA 416, IRGA 417, Avaxi (short cycle) and BRS-Fronteira (medium cycle); as well as ten barnyardgrass populations. The second trial treatments were flooding timings: 1,10 and 20 DAT (days after herbicide treatment) and barnyardgrass populations. The estimated EWT for barnyardgrass varied in function of the adopted management practices in the flooded rice crop. The estimated EWT for rice IRGA 416 and 417 was greater than that of the other cultivars when in barnyardgrass competition. Flooding timing delay reduced EWT for the BRS-Pelota rice variety. Increased potential yield losses, product
\end{abstract}

1 Recebido para publicação em 7.5.2007 e na forma revisada em 29.11.2007.

Parte da dissertação de mestrado do primeiro autor apresentada ao Programa de Pós-Graduação em Fitossanidade da UFPel Pelotas-RS; ${ }^{2}$ Eng ${ }^{\circ}$-Agr ${ }^{\circ}$, aluno do Programa de Pós-Graduação em Fitossanidade da Universidade Federal de Pelotas - UFPel, Caixa

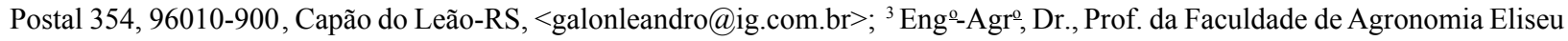
Maciel da UFPel (Bolsista do CNPq); ${ }^{4}$ Aluno de graduação da Faculdade de Agronomia Eliseu Maciel - UFPel. 
value and herbicide efficiency as well as reduced control price reduced EWT, rendering viable the adoption of management practices at low barnyardgrass density when competing with flooded rice.

Keywords: economic study, integrated management, mathematical models.

\section{INTRODUÇÃO}

O capim-arroz é uma das mais importantes plantas daninhas da agricultura mundial, sendo relatada como planta competidora em mais de 36 culturas em 61 países (Norris et al., 2001). O controle dessa planta nas lavouras de arroz irrigado tornou-se prática obrigatória, o que é feito por meio da aplicação de herbicidas pré ou pós-emergentes seletivos para a cultura (Sosbai, 2005). Contudo, o custo de controle do capim-arroz, ao utilizar herbicidas, representa um dos principais componentes do custo de produção. Além disso, as preocupações crescentes com o potencial de impacto ambiental causado pelos herbicidas incentivaram reduções no seu uso intensivo (Mcdonald \& Riha, 1999; Rizzardi \& Fleck, 2004). Isso conduz a uma mudança no sistema de cultivo: em vez de se buscar o controle das plantas daninhas, a ênfase atual é o manejo de suas populações com base no conceito de nível de dano ec on ôm ic o (NDE) (O nofri \& Tei, 1994; Vandevender et al., 1997; Agostinetto et al., 2005).

Pelo conceito de NDE, a aplicação de herbicidas ou de outros métodos de controle somente se justificará caso os prejuízos causados pelas plantas daninhas sejam superiores ao custo da medida utilizada (Lindquist et al., 1996; Pester et al., 2000). Elevadas populações de plantas daninhas competindo com as culturas simplificam a tomada de decisão dos produtores para adotarem alguma medida de controle (Knezevic et al., 1997). No entanto, quando as plantas daninhas aparecem em baixas densidades populacionais, a adoção de medidas para controlá-las torna-se dificil, pois os agricultores precisam quantificar as vantagens econômicas associadas ao custo do controle (Knezevic et al., 1997). Assim, é necessário implementar estratégias de manejo que integrem o conhecimento técnico e a análise econômica, aliado ao conhecimento da relação de competição entre a cultura e as plantas daninhas (Beckett et al., 1988).

O conhecimento da dinâmica e da competitividade das plantas daninhas é pressuposto fundamental, pois, para algumas espécies, pode se tomar a decisão de não controlá-las, devido à baixa competitividade; entretanto, pressupõe-se que para espécies competitivas, como capim-arroz, o controle, na maioria dos casos, deva ser necessário (Norris, 1992; Cardina et al., 1995). Baixas populações ou populações-escape de capim-arroz podem produzir elevadas quantidades de sementes, suficientes para gerar elevadas populações no próximo ano agrícola (Norris, 1992).

Quando se utiliza o NDE para tomada de decisão de controle de plantas daninhas presentes nas lavouras, comparam-se as perdas estimadas de produtividade de grãos das culturas aos custos das opções de controle disponíveis, proporcionando assim a análise do ganho obtido com o tratamento de controle usado (Bauer \& Mortensen, 1992). Para estimar o $\mathrm{NDE}$, adotam-se usualmente equações de regressão ou funções de dano, já que estas relacionam as perdas de produtividade das culturas com possiveis medidas da infestação das plantas daninhas na época do seu controle em pós-emergência (Weaver, 1991).

No cálculo dos NDEs são envolvidas muitas variáveis, e estas podem ser influenciadas por vários fatores, como: espécie de planta daninha presente na lavoura, população e época de emergência das plantas daninhas em relação à cultura, porcentagem de perda da produtividade da cultura, potencial de produtividade da cultura na ausência de plantas daninhas, valor do produto colhido, custos e eficiência do controle e influência das plantas 
daninhas remanescentes sobre o produto (Knezevic et al., 1997).

Entre os vários elementos que exercem influência na competição entre as plantas daninhas e as culturas citam-se aqueles relacionados com as práticas de manejo, como o uso de cultivares com maior habilidade competitiva e épocas de entrada de água na lavoura, que podem diminuir o grau de competição das plantas daninhas, aumentando o NDE e minimizando a necessidade de adoção de medidas de controle. Quando essas informações estão disponiveis, elas podem ter uma função importante no sentido de mudar o método de manejo que depende principalmente de herbicidas, para um sistema voltado ao conhecimento ecofisiológico (Bauer \& Mortensen, 1992; McDonald \& Riha, 1999). A hipótese testada foi de que existem variações nos niveis de dano econômico ocasionados pela competição exercida pelo capim-arroz com o arroz irrigado, em função de população de plantas do competidor, de cultivares e de épocas de entrada de água na lavoura.

Objetivou-se com o trabalho avaliar niveis de dano econômico para capim-arroz em competição com arroz irrigado, estimados em função de variações nas populações do competidor, de cultivares de arroz e de épocas de entrada de água na lavoura.

\section{MATERIAL E MÉTODOS}

Foram conduzidos dois experimentos em campo, no Centro Agropecuário da Palma da Universidade Federal de Pelotas (CAP/UFPel), no município de Capão do Leão, RS, no ano agrícola 2005/06, que passam a ser descritos como primeiro e segundo experimentos, respectivamente. O delineamento experimental utilizado nos experimentos foi o completamente casualizado, com uma unidade experimental por tratamento. Nesta pesquisa, as populações de capim-arroz funcionaram como repetições, dando a variância necessária para as análises estatísticas.

No primeiro experimento, os tratamentos foram constituídos de cultivares de arroz e populações da planta competidora: capim-arroz. Este foi estabelecido em 10 populações, obtendo-se populações máximas de 622, 238,
$396,532,888$ e 434 plantas $\mathrm{m}^{-2}$ para os cultivares BRS-Atalanta e IRGA 421 (ciclo muito curto), IRGA 416, IRGA 417 e Avaxi (ciclo curto) e BRS-Fronteira (ciclo médio), respectivamente, sendo avaliados no início do ciclo de desenvolvimento (Sosbai, 2005). As diferenças observadas nas populações de capim-arroz em competição com os cultivares podem ser decorrentes de suas diferenças morfofisiológicas, as quais interferem na interceptação e utilização da radiação solar, afetando conseqüentemente a habilidade competitiva da cultura.

No segundo experimento, os tratamentos foram constituídos de épocas de entrada de água: 1,10 e 20 dias após aplicação dos tratamentos herbicidas (DAT) e populações de capim-arroz, que variaram de zero (0) até 222 plantas $\mathrm{m}^{-2}$, competindo com o arroz irrigado cultivar BRS-Pelota.

O preparo do solo para instalação dos experimentos foi feito em sistema de cultivo convencional, incluindo aração e gradagem. As unidades experimentais ocuparam área de $11,05 \mathrm{~m}^{2}$, sendo a semeadura realizada em fileiras espaçadas de $0,17 \mathrm{~m}$. Nos dois experimentos, a densidade de semeadura dos cultivares de arroz foi de $125 \mathrm{~kg} \mathrm{ha}^{-1}$, o que proporcionou estabelecimento de população aproximada de 400 plantas $\mathrm{m}^{-2}$, à exceção do híbrido Avaxi, em que a densidade de semeadura foi de $50 \mathrm{~kg} \mathrm{ha}^{-1}$, obtendo-se população aproximada de 160 plantas $\mathrm{m}^{-2}$ (Sosbai, 2005). As demais práticas de manejo utilizadas foram aquelas recomendadas pela pesquisa para a cultura do arroz irrigado (Sosbai, 2005).

As populações dos competidores foram compostas pelas espécies Echinochloa colona e E. crusgalli, que foram estabelecidas a partir do banco de sementes do solo, por meio da aplicação do herbicida cyhalofop-butyl na dose de $270 \mathrm{~g} \mathrm{ha}^{-1}+$ adjuvante Iharol $\left(1,5 \mathrm{~L} \mathrm{ha}^{-1}\right)$. As plantas de capim-arroz foram protegidas com copos ou chapas plásticas, para que não sofressem danos do herbicida. As demais plantas daninhas remanescentes nas unidades experimentais foram controladas através de monda. O herbicida cyhalofop-butyl foi escolhido devido ao controle de capim-arroz, à seletividade à cultura e por não persistir no solo e/ou na água (Vencill, 2002). 
As avaliações de populações de plantas de capim-arroz foram realizadas 28 e 21 dias após a emergência da cultura (DAE), para o primeiro e segundo experimentos, respectivamente, as quais abrangeram contagens dos indivíduos em duas áreas de $0,25 \mathrm{~m}^{2}(0,5 \times 0,5 \mathrm{~m})$ em cada unidade experimental. A quantificação da produtividade de grãos do arroz foi obtida pela colheita das panículas em área útil de $4,5 \mathrm{~m}^{2}$ $(3 \times 1,5 \mathrm{~m})$, de cada unidade experimental, quando o teor de umidade dos grãos atingiu aproximadamente $22 \%$. Após pesagem dos grãos, determinou-se sua umidade, sendo as massas corrigidas para teor de $13 \%$ de umidade.

As perdas percentuais de produtividade de grãos, em relação às unidades experimentais livres de plantas concorrentes, foram calculadas de acordo com a equação 1 :

Perda $(\%)=\left(\frac{\mathrm{Ra}-\mathrm{Rb}}{\mathrm{Ra}}\right) \times 100 \quad$ equação 1

em que $R a$ e $R b$ : produtividade da cultura sem ou com presença da planta competidora (capim-arroz), respectivamente.

Aos dados obtidos ajustou-se o modelo de regressão não-linear da hipérbole retangular (Cousens, 1985), conforme a Equação 2:

$$
\mathrm{Pp}=\frac{\left(\mathrm{i}^{*} \mathrm{X}\right)}{\left(1+\left(\frac{i}{a}\right) * X\right)} \quad \text { Equação } 2
$$

em que $\mathrm{Pp}=$ perda de produtividade $(\%) ; X=$ população de capim-arroz; e $i$ e $a=$ perdas de produtividade $(\%)$ por unidade de plantas de capim-arroz quando o valor da variável se aproxima de zero e quando tende ao infinito, respectivamente.

O ajuste dos dados ao modelo foi realizado com o procedimento Proc Nlin, do programa computacional SAS (SAS, 1989). Para o procedimento de cálculos, utilizou-se o método de Gauss-Newton, o qual, por sucessivas iterações, estima os valores dos parâmetros, nos quais a soma dos quadrados dos desvios das observações, em relação aos valores ajustados, seja minima (Ratkowsky, 1983).

No cálculo do nível de dano econômico (NDE) utilizaram-se as estimativas do parâmetro $i$ obtidas a partir da Equação 2 (Cousens, 1985) e a equação adaptada de Lindquist \& Kropff (1996) - Equação 3:

$$
\mathrm{NDE}=\frac{(\mathrm{Cc})}{\left(\mathrm{R}^{*} \mathrm{P} *\left(\frac{\mathrm{i}}{100}\right) *\left(\frac{\mathrm{H}}{100}\right)\right)}
$$

Equação 3

em que NDE = nível de dano econômico (plantas $\mathrm{m}^{-2}$ ); $C c=$ custo do controle (herbicida e aplicação terrestre tratorizada, em dólares $\mathrm{ha}^{-1}$ ); $R=$ produtividade de grãos de arroz $\left(\mathrm{kg} \mathrm{ha}^{-1}\right)$; $P=$ preço do arroz (dólares $\mathrm{kg}^{-1}$ de grãos); $i=$ perda $(\%)$ de produtividade do arroz por unidade de planta competidora quando o nível populacional se aproxima de zero; e $H=$ nivel de eficiência do herbicida (\%).

Para as variáveis $C c, R, P$ e $H$ (Equação 3) foram estimados três valores. Assim, no custo de controle $(\mathrm{Cc})$ considerou-se o preço médio de US\$ 87 ha $^{-1}$ (270 $\mathrm{g} \mathrm{ha}^{-1}$ de cyhalofop-butyl + adjuvante), sendo o custo máximo e o mínimo alterados em $25 \%$, em relação ao custo médio. A produtividade de grãos de arroz $(R)$ baseouse na menor (4.440 kg ha-1), média (5.580 kg ha $\left.{ }^{-1}\right)$ e maior (6.680 kg ha-1) produtividades obtidas no RS nos últimos 10 anos (Irga, 2006). O preço do produto $(P)$ foi estimado a partir do menor (US\$ 6,00), médio (US\$ 9,00) e maior (US\$ 14,00) preços do arroz pagos por saca de $50 \mathrm{~kg}$ nos últimos 10 anos (Irga, 2006). Os valores da eficiência do herbicida $(H)$ foram estabelecidos na ordem de 80,90 e $100 \%$ de controle, sendo $80 \%$ o controle mínimo considerado eficaz da planta daninha (Sosbai, 2005).

Nas simulações de NDE utilizaram-se os valores intermediários para as variáveis que não estavam sendo objeto de cálculo.

\section{RESULTADOS E DISCUSSÃO}

A simulação dos valores de NDE foi realizada utilizando-se a variável explicativa população de plantas (PP) de capim-arroz, em razão de esta apresentar melhor ajuste ao modelo da hipérbole retangular. A comparação da competitividade relativa entre espécies demonstrou diferenciação no grau de competição do capim-arroz em função do cultivar (Tabela 1). Isso pode decorrer das características intrinsecas de cada cultivar, que respondem de 
Tabela 1 - Perda de produtividade de grãos do arroz irrigado em função de população de capim-arroz (plantas $\mathrm{m}^{-2}$ ) e cultivares de arroz, 28 DAE. CAP/UFPel, Capão do Leão-RS, 2005/06

\begin{tabular}{|l|c|c|c|c|c|}
\hline \multicolumn{1}{|c|}{ Cultivar } & Ciclo & Perda de produtividade $(\%)^{I^{\prime \prime}}$ & $\left(\mathrm{R}^{2}\right)^{\frac{1}{\prime}}$ & $\left(\mathrm{F}^{*}\right)^{\underline{1}^{\prime}}$ & $(\mathrm{QMR})^{1^{\prime}}$ \\
\hline BRS-Atalanta & muito curto & $(11,38 . \mathrm{X}) /(1+(11,38 / 96,19) . \mathrm{X}]$ & 0,86 & 196,63 & 163,20 \\
\hline IRGA 421 & muito curto & $(9,79 . \mathrm{X}) /[1+(9,79 / 108,30) . \mathrm{X}]$ & 0,91 & 193,74 & 136,20 \\
\hline IRGA 416 & curto & $(7,22 . \mathrm{X}) /[1+(7,22 / 112,50) . \mathrm{X}]$ & 0,87 & 67,60 & 372,50 \\
\hline IRGA 417 & curto & $(4,71 . \mathrm{X}) /[1+(4,71 / 107,10) . \mathrm{X}]$ & 0,94 & 273,96 & 77,48 \\
\hline AVAXI & curto & $(29,27 . \mathrm{X}) /[1+(29,27 / 94,27) . \mathrm{X}]$ & 0,90 & 362,55 & 100,60 \\
\hline BRS-Fronteira & médio & $(13,67 . \mathrm{X}) /[1+(13,67 / 101,10) . \mathrm{X}]$ & 0,95 & 382,45 & 69,37 \\
\hline
\end{tabular}

${ }_{1}^{1 /}$ Valor obtido pelo modelo de regressão da hipérbole retangular (Cousens, 1985). *Significativo $(\mathrm{p} \leq 0,05)$.

maneira diferenciada à competição de plantas daninhas (Fischer et al., 1997).

Cultivares de arroz que apresentam maior habilidade competitiva reduzem a intensidade de competição das plantas daninhas e, conseqüentemente, diminuem o uso de herbicidas e o custo de produção. Nesse sentido, pesquisas que avaliaram a competição de diferentes cultivares de arroz com plantas daninhas detectaram existir variabilidade na habilidade competitiva entre diferentes cultivares de arroz (Ni et al., 2000; Balbinot Jr. et al., 2003; Fleck et al., 2004).

O êxito na implantação de sistema de controle do capim-arroz, na cultura do arroz irrigado, pode decorrer da determinação da população que excede o NDE. Assim, observou-se que os cultivares IRGA 416 ou 417 (ciclo curto) apresentaram maiores valores de NDE em todas as simulações realizadas, os quais variaram de 0,86 a 3,07 plantas $\mathrm{m}^{-2}$ (Figuras 1, 2, 3 e 4).

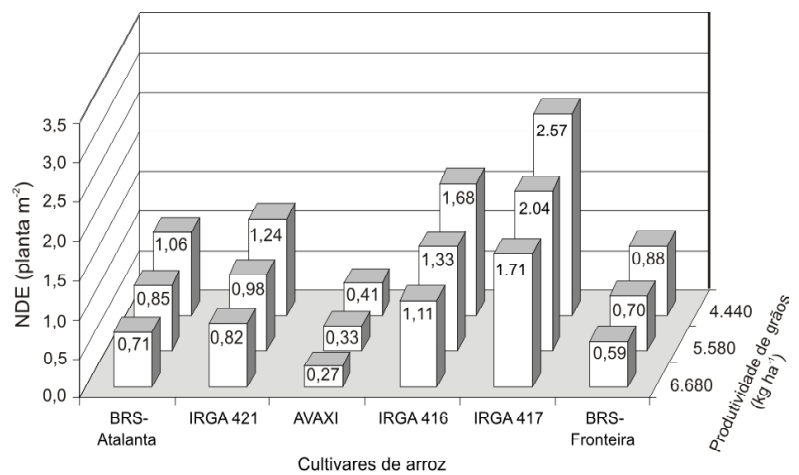

Figura 1 - Nível de dano econômico (NDE) para arroz irrigado em função de produtividade de grãos, população de capimarroz e cultivares de arroz. CAP/UFPel, Capão do LeãoRS, 2005/06.
O cultivar Avaxi (ciclo curto) apresentou menores valores de NDE, com variação de 0,21 a 0,49 plantas $\mathrm{m}^{-2}$ (Figuras 1, 2, 3 e 4). Isso pode ser decorrência da menor densidade de semeadura, o que pode ter permitido maior passagem de radiação e conseqüente melhor estabelecimento das plantas de capim-arroz. De acordo com Fleck et al. (2003), cultivar de arroz que apresenta baixa cobertura do solo oferece maior penetração de luz no dossel da comunidade e menor competitividade com as plantas daninhas.

Na média de todos os cultivares e comparando a menor com a maior produtividade de grãos, observa-se diferença no NDE da ordem de 66\% (Figura 1). Assim, quanto mais elevado o potencial de produtividade da cultura, menor será a população de plantas de capim-arroz necessária para superar o NDE, tornando compensatória a adoção de medidas de controle da planta daninha.

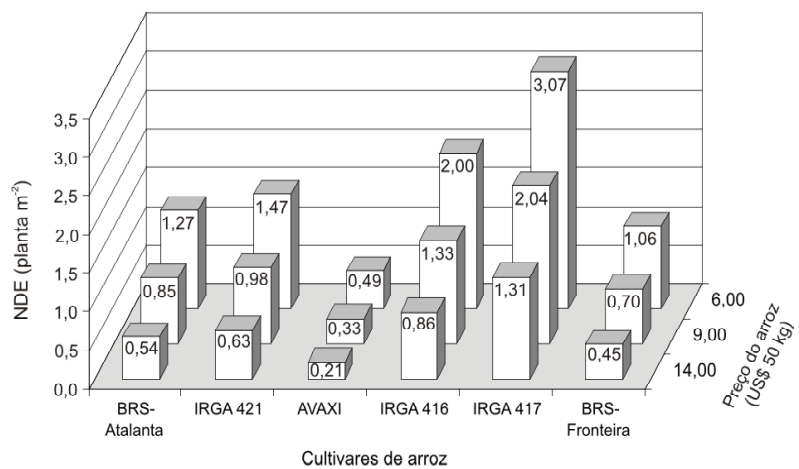

Figura 2 - Nível de dano econômico (NDE) para arroz irrigado em função de preço do arroz, população de capim-arroz e cultivares de arroz. CAP/UFPel, Capão do Leão-RS, 2005/ 06.

Planta Daninha, Viçosa-MG v. 25, n. 4, p. 709-718, 2007 


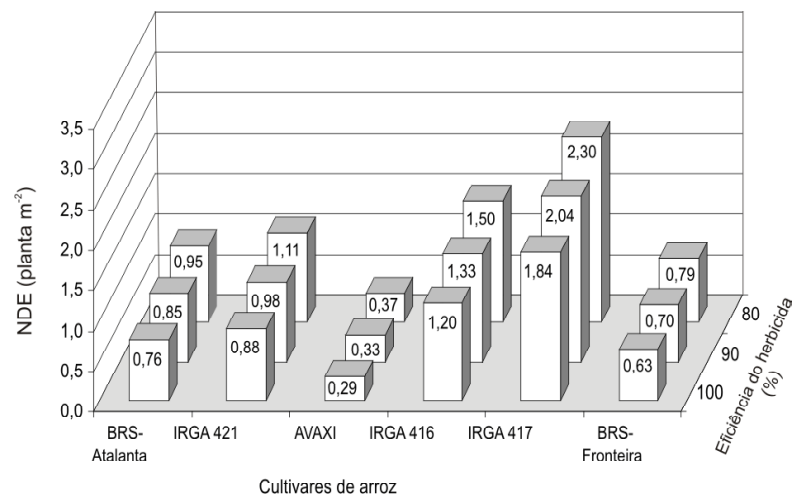

Figura 3 - Nível de dano econômico (NDE) para arroz irrigado em função de eficiência do herbicida, população de capimarroz e cultivares de arroz. CAP/UFPel, Capão do LeãoRS, 2005/06.

Os resultados médios de todos os cultivares testados, do maior contra o menor preço pago pela saca de arroz, demonstraram variação de 2,3 vezes no valor do NDE (Figura 2). Desse modo, quanto menor o preço pago pela saca de arroz, mais elevadas serão as populações de capim-arroz necessárias para ultrapassar o NDE e compensar o tratamento de controle.

Ao comparar a eficiência média do herbicida $(90 \%)$, em relação à menor $(80 \%)$ ou à maior $(100 \%)$, observaram-se alterações nos NDEs de aproximadamente $11 \%$ quando os cultivares de arroz competiram com o capim-arroz (Figura 3). Assim, o nivel de controle influencia o NDE, e, quanto mais elevada a eficiência do herbicida, menor o NDE (menor o número de plantas de capim-arroz $\mathrm{m}^{-2}$ necessárias para adotar medidas de controle).

Ao analisar o custo médio de controle do capim-arroz, para todos os cultivares, verificou-se que o custo mínimo foi $40 \%$ inferior ao custo máximo (Figura 4). Quanto mais elevado o custo, maiores são os NDEs e mais plantas

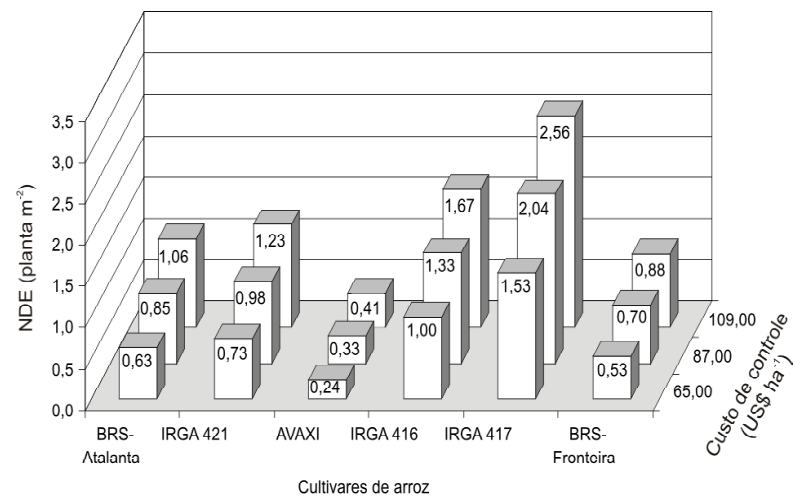

Figura 4 - Nível de dano econômico (NDE) para arroz irrigado em função de custo de controle, população de capim-arroz e cultivares de arroz. CAP/UFPel, Capão do Leão-RS, 2005/ 06.

de capim-arroz $\mathrm{m}^{-2}$ são necessárias para justificar medidas de controle.

No segundo experimento, os valores estimados para o parâmetro $i$ variaram de 8,40 a 11,25 (Tabela 2). O menor valor para o parâmetro $i$ foi obtido para a época antecipada de entrada de água na lavoura. Ao atrasar a época de entrada de água na lavoura em 10 e 20 DAT, aumentaram os valores do parâmetro $i$ em 24 e $34 \%$, respectivamente, quando comparado a 1 DAT. Os resultados indicam que a antecipação do início da irrigação aumenta a competitividade da cultura com o capim-arroz. A presença da lâmina de água em estádio precoce de desenvolvimento da cultura provoca mudanças relacionadas aos aspectos fisiológicos das plantas e às características pedogenéticas do solo, interferindo na disponibilidade de nutrientes, bem como no controle de pragas.

As estimativas obtidas para o NDE, no segundo experimento, variaram de 0,74 a 1,72 ; 0,59 a 1,39 ; e 0,55 a 1,28 plantas $\mathrm{m}^{-2}$ de capimarroz, considerando-se as épocas de entrada

Tabela 2 - Perda de produtividade de grãos de arroz irrigado, cultivar BRS-Pelota, em função de população de capim-arroz (plantas $\mathrm{m}^{-2}$ ) e épocas de entrada de água, aos 21 DAE. CAP/UFPel, Capão do Leão-RS, 2005/06

\begin{tabular}{|c|c|c|c|c|}
\hline Entrada de água (DAT) $)^{\frac{2}{2}}$ & Perda de produtividade $(\%)^{1 /}$ & $\left(\mathrm{R}^{2}\right)^{\mathrm{I}^{\prime}}$ & $\left(\mathrm{F}^{*}\right)^{\mathbf{1}^{\prime}}$ & $(\mathrm{QMR})^{1}$ \\
\hline 01 & $(8,40 . X) /(1+(8,40 / 99,09) \cdot X]$ & 0,89 & 138,53 & 130,60 \\
\hline 10 & $(10,40 \cdot X) /(1+(10,40 / 104,30) \cdot X]$ & 0,97 & 364,73 & 62,60 \\
\hline 20 & $(11,25 \cdot X) /(1+(11,25 / 97,41) \cdot X]$ & 0,84 & 177,06 & 209,30 \\
\hline
\end{tabular}

${ }^{1}$ Valor obtido pelo modelo de regressão da hipérbole retangular (Cousens, 1985). * Significativo (p $\left.\leq 0,05\right) .{ }^{2}$ Dias após aplicação dos tratamentos herbicidas. 
de água de 1,10 e 20 DAT, respectivamente (Figuras 5, 6, 7 e 8).

Com base nos valores médios das estimativas de NDE para produtividade de grãos, observou-se que os NDEs reduziram em 19 e $25 \%$ para as entradas de água aos 10 e 20 DAT, respectivamente, quando comparado a 1 DAT (Figura 5).

Os resultados demonstram redução nos valores de NDE com o atraso da época de entrada de água, em todas as simulações (Figuras $5,6,7$ e 8). Usando como referência a produtividade média de grãos de arroz, observou-se que a entrada de água ao 1 DAT reduziu o NDE em 20 e $25 \%$, respectivamente, comparativamente à entrada de água aos 10 e 20 DAT (Figura 5).

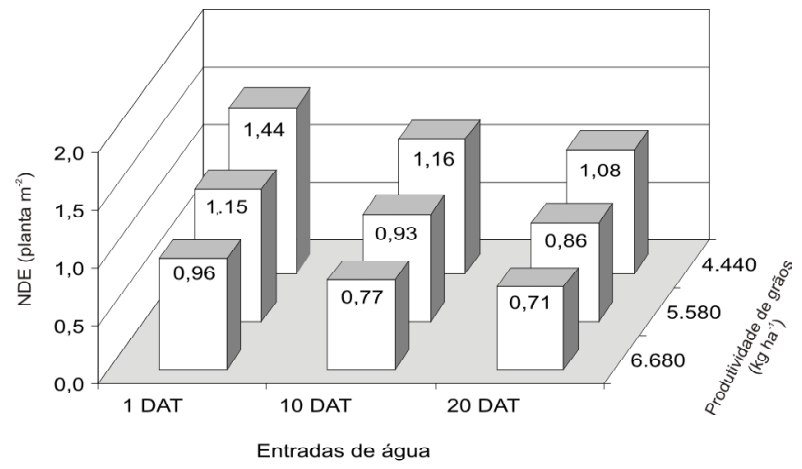

Figura 5 - Nível de dano econômico (NDE) para arroz irrigado, cultivar BRS-Pelota, em função de produtividade de grãos, população de capim-arroz e épocas de entrada de água. CAP/UFPel, Capão do Leão-RS, 2005/06.

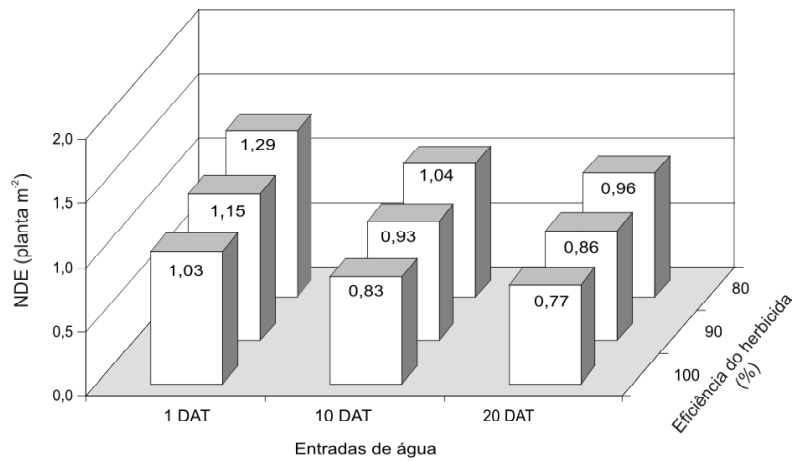

Figura 7 - Nível de dano econômico (NDE) para arroz irrigado, cultivar BRS-Pelota, em função de eficiência do herbicida, população de capim-arroz e épocas de entrada de água. CAP/UFPel, Capão do Leão-RS, 2005/06.
Com relação à variável preço pago ao arroz, observou-se que os NDEs aumentaram com a diminuição do preço nas três épocas de entrada de água (Figura 6). No entanto, a redução do preço do arroz de 14 para 6 dólares aumentou o NDE em cerca de $132 \%$. Isso demonstra que, quanto menor o preço do arroz, maior será a população de capim-arroz $\mathrm{m}^{-2}$ necessária para compensar a realização de controle.

Ao analisar a variável eficiência do herbicida, adotando-se $90 \%$ de controle, observouse que os NDEs apresentaram decréscimos de 20 e $25 \%$ ao atrasar em 10 e 20 DAT a entrada de água na lavoura (Figura 7).

Considerando as épocas de entrada de água na lavoura e tendo por base os valores médios das estimativas para todas as variáveis analisadas, observou-se a seguinte ordem

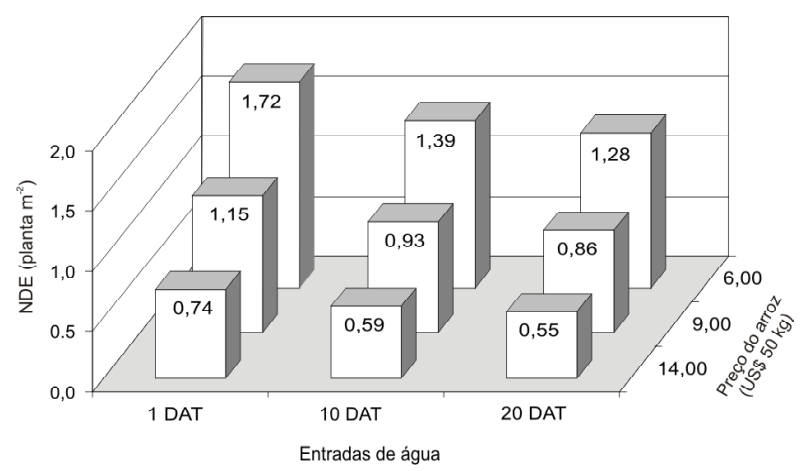

Figura 6 - Nível de dano econômico (NDE) para arroz irrigado, cultivar BRS-Pelota, em função de preço do arroz, população de capim-arroz e épocas de entrada de água. CAP/UFPel, Capão do Leão-RS, 2005/06.

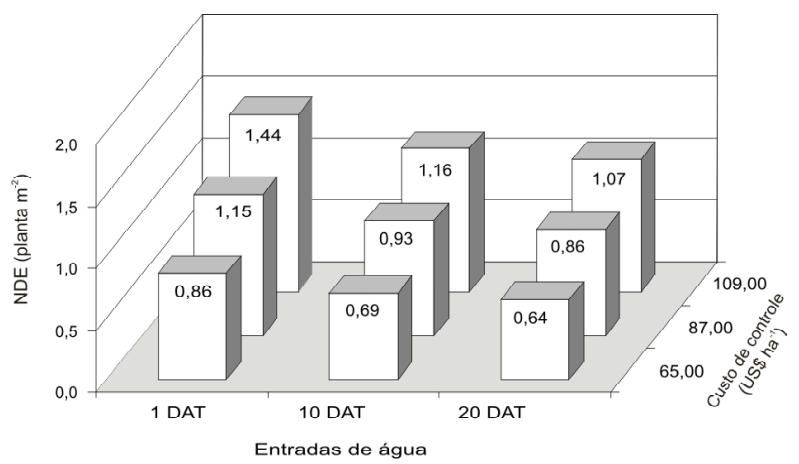

Figura 8 - Nível de dano econômico (NDE) para arroz irrigado, cultivar BRS-Pelota, em função de custo de controle, população de capim-arroz e épocas de entrada de água. CAP/UFPel, Capão do Leão-RS, 2005/06. 
decrescente nos valores de NDE: 1 DAT > 10 DAT > 20 DAT (Figuras 5, 6, 7 e 8). Os menores NDEs observados para as entradas de água mais tardias na lavoura podem decorrer do baixo controle ou de possiveis fluxos de emergência do capim-arroz, já que a lâmina de água evita a germinação das plântulas do capimarroz, através do método físico (Freitas, 2004).

Aumentos no potencial de produtividade da cultura, no preço do produto colhido ou na eficiência do herbicida e redução no custo de controle diminuiram os NDEs em todas as simulações efetuadas, independentemente dos fatores em teste. Assim, em lavouras onde as estimativas do potencial de produtividade são elevadas, a menor população de plantas daninhas justifica economicamente a adoção de medidas de controle.

O acréscimo no custo de controle elevou os NDEs para as três épocas de entrada de água testadas (Figura 8). Verificou-se que as estimativas dos NDEs variaram de 0,86 a 1,$44 ; 0,69$ a 1,16; e 0,64 a 1,07 para as entradas de água de 1,10 e 20 DAT, respectivamente. Desse modo, ao se compararem os valores médios dos NDEs em relação aos custos de controle e às épocas de entrada de água, observou-se que houve acréscimos de 80 e $75 \%$ nos NDEs quando se atrasou a entrada de água em 10 e 20 DAT, respectivamente, comparativamente com 1 DAT.

Os resultados evidenciam que a aplicação prática do conceito de NDE para a tomada de decisão de controlar plantas daninhas em pósemergência, levando em consideração um único ano agrícola, pode apresentar limitações. Os principais fatores que podem limitar o uso do NDE são: dificuldade em elaborar metodologias simples e baratas para quantificar os efeitos da competição de plantas daninhas sobre as culturas; ocorrência de elevada diversidade de espécies de plantas daninhas; impacto de fatores ambientais na interação cultura com plantas daninhas em diferentes locais e anos; e aumento do banco de semente no solo pelas plantas de capim-arroz em anos subseqüentes (Kropff \& Sppiters, 1991; Swinton et al., 1994).

Os valores de NDE poderiam diminuir consideravelmente caso fosse incluída a variável produção de sementes, aumentando a necessidade de adoção de medidas de controle (Coble \& Mortensen, 1992). Quando se opta por não controlar uma determinada população de planta daninha, deve-se ter claro que uma única planta tolerada poderá reproduzir várias plantas nas safras seguintes (Norris, 1992). Nesse sentido, trabalhos propõem a redução do NDE para um nivel de dano econômico ótimo (NDEO) ao se considerar também a produção de sementes como variável (Bauer \& Mortensen, 1992; Fleck et al., 2002).

O uso do NDE como ferramenta para o manejo de plantas daninhas precisa superar suas limitações inerentes, já que sua implantação somente se justifica nas lavouras que utilizem outras práticas de manejo das populações de plantas daninhas não controladas, como: rotação de culturas, arranjo adequado de plantas, uso de cultivares mais competitivos e épocas adequadas para entrada de água na lavoura.

Os niveis de dano econômico para o capim-arroz variam em função de cultivares de arroz, de épocas de entrada de água na lavoura e de populações da planta daninha. A utilização dos cultivares de arroz IRGA 416 e IRGA 417 e a entrada de água na lavoura um dia após a aplicação dos tratamentos herbicidas aumentaram o nivel de dano econômico em arroz irrigado. Aumentos nas perdas de produtividade por unidade de planta daninha, no potencial de produtividade da cultura, no valor do produto colhido e na eficiência do herbicida e diminuição do custo de controle reduziram os NDEs, tornando econômica a adoção de práticas de manejo sob menores populações de capim-arroz em competição com arroz irrigado.

\section{AGRADECIMENTOS}

À Coordenação de Aperfeiçoamento de Pessoal de Nivel Superior (CAPES), à Fundação de Amparo à Pesquisa do Estado do Rio Grande do Sul (FAPERGS) e ao Conselho Nacional de Desenvolvimento Científico e Tecnológico (CNPq), pelas concessões de bolsas.

\section{LITERATURA CITADA}

AGOSTINETTO, D. et al. Dano econômico como critério na decisão sobre manejo de genótipos de arroz concorrentes em arroz irrigado. Pesq. Agropec. Bras., v. 40, p. 1-9, 2005. 
BALBINOT JR., A. A. et al. Competitividade de cultivares de arroz irrigado com cultivar simuladora de arroz-vermelho. Pesq. Agropec. Bras., v. 38, p. 53-59, 2003.

BAUER, T. A.; MORTENSEN, D. A. A comparison of economic and economic optimum thresholds for two annual weeds in soybeans. Weed Technol., v. 6, p. 228-235, 1992.

BECKETT, T. H.; STOLLER, E. W.; WAX, L. M. Interference of four annual weeds in corn (Zea mays). Weed Sci., v. 36, p. 764-769, 1988.

CARDINA, J.; REGNIER, E.; SPARROW, D. Velvetleaf (Abutilon theophrasti) competition and economic thresholds in conventional and no-till corn (Zea mays). Weed Sci., v. 43, p. 81-87, 1995.

COBLE, H. D.; MORTENSEN, D. A. The threshold concept and its application to weed science. Weed Technol., v. 6, p. 191-195, 1992.

COUSENS, R. An empirical model relating crop yield to weed and crop density and a statistical comparison with other models. J. Agric. Sci., v. 105, p. 513-521, 1985.

FISCHER, A.; RAMIREZ, H. V.; LOZANO, J. Suppression of junglerice (Echinochloa colona (L.) Link) by irrigated rice cultivars in Latin America. Agron. J., v. 89, p. 516-521, 1997.

FLECK, N. G.; RIZZARDI, M. A.; AGOSTINETTO, D. Nível de dano econômico como critério para tomada de decisão no controle de guanxuma em soja. Planta Daninha, v. 20, p. 421-429, 2002.

FLECK, N. G. et al. Velocidade de estabelecimento em cultivares de arroz irrigado como característica para aumentar a habilidade competitiva com plantas concorrentes. Ci. Rural, v. 33, p. 635-640, 2003.

FLECK, N. G. et al. Interferência de plantas concorrentes em arroz irrigado modificada por métodos culturais. Planta Daninha, v. 22, n. 1, p. 19-28, 2004.

FREITAS, G. D. Desempenho do arroz (Oryza sativa L.) cultivar BRS-Pelota e controle de capim-arroz (Echinochloa spp.) submetidos a quatro épocas de entrada d'água após a aplicação de doses reduzidas de herbicidas. 2004. 54 f. Dissertação (Mestrado em Produção Vegetal) - Universidade Federal de Pelotas, Pelotas, 2004.

INSTITUTO RIO-GRANDENSE DO ARROZ - IRGA. Arroz irrigado no RS: área, produção e rendimento. Disponível em: < http://www.irga.rs.gov.br $>$ Acesso em: 5.10.2006.
KNEZEVIC, S.Z.; HORAK, M.J.; VANDERLIP, R.L. Relative time of redroot pigweed (Amaranthus retroflexus L.) emergence is critical in pigweed-sorghum [Sorghum bicolor (L.) Moench] competition. Weed Sci., v. 45, p. 502-508, 1997.

KROPFF, M. J.; SPITTERS, C. J. T. A simple model of crop loss by weed competition from early observations on relative leaf area of weeds. Weed Res., v. 31, p. 97-105, 1991.

LINDQUIST, J. L. et al. Stability of corn (Zea mays)velvetleaf (Abutilon theophrasti) interference relationships. Weed Sci., v. 44, p. 309-313, 1996.

LINDQUIST, J. L.; KROPFF, M. J. Application of an ecophysiological model for irrigated rice (Oryza sativa) Echinochlo a competition. Weed Sci., v. 44, p. 52-56, 1996.

McDONALD, A. J.; RIHA, S. J. Model of crop: weed competition applied to maize: Abutilon theophrasti interactions. II. Assessing the impact of climate: implications for economic thresholds. Weed Res., v. 39, p. 371-381, 1999.

NI, H. et al. Oryza sativa plant traits conferring competitive ability against weeds. Weed Sci., v. 48, p. 200-204, 2000.

NORRIS, R. F. Case history for weed competition population ecology: barnyardgrass (Echinochloa crus-galli) in sugarbeets (Beta vulgaris). Weed Technol., v. 6, p. 220227, 1992.

NORRIS, R. F. et al. Spatial arrangement, density, and competition between barnyardgrass and tomato: I. Crop growth and yield. Weed Sci., v. 49, p. 61-68, 2001.

ONOFRI, A.; TEI, F. Competitive ability and threshold levels of three broadleaf weed species in sunflower. Weed Res., v. 38, p. 471-479, 1994.

PESTER, T. A. et al. Secale cereale interference and economic thresholds in winter Triticum aestivum. Weed Sci., v. 48, p. 720-727, 2000.

RATKOWSKY, D. A. Nonlinear regression modeling: a unified practical approach. New York: Marcel Dekker, 1983. p. $135-154$.

RIZZARDI, M.A.; FLECK, N.G. Dose ótima de acifluorfen + bentazon para controle de picão-preto e guanxuma em soja. Planta Daninha, v. 22, p. 117-125, 2004. 
SOCIEDADE SUL-BRASILEIRA DE ARROZ IRRIGADO - SOSBAI: Arroz irrigado: Recomendações técnicas da pesquisa para o Sul do Brasil. Santa Maria: Universidade Federal de Santa Maria, 2005. 159 p.

STATISTICAL ANALYSIS SYSTEM - SAS. User's guide. 4.ed. Cary: 1989. 846 p.

SWINTON, S. M. et al. Estimation of crop yield loss due to interference by multiple weed species. Weed Sci., v. 42, p. 103-109, 1994.
VANDEVENDER, K. M.; COSTELLO, T. A.; SMITH JR., R. J. Model of rice (Oryza sativa) yield reduction as a function of weed interference. Weed Sci., v. 45, p. 218-224, 1997.

VENCILL, W. K. (Ed.). Herbicide handbook. 8.ed. Lawrence: Weed Science Society of America, 2002. $493 \mathrm{p}$.

WEAVER, S. E. Size-depen dent economic thresholds for broadleaf weed species in soybeans. Weed Technol., v. 5, p. 674-679, 1991. 